\title{
Association between the 21-gene recurrence score and isolated locoregional recurrence in stage I-II, hormone receptor- positive breast cancer
}

David D. Yang ${ }^{1,2+}$, Daniela L. Buscariollo ${ }^{1,2+}$, Angel M. Cronin ${ }^{3}$, Shicheng Weng ${ }^{3}$, Melissa E. Hughes ${ }^{4}$, Richard J. Bleicher ${ }^{5}$, Adam L. Cohen ${ }^{6}$, Sara H. Javid ${ }^{7}$, Stephen B. Edge ${ }^{8}$, Beverly Moy ${ }^{1,9}$, Joyce C. Niland ${ }^{10}$, Antonio C. Wolff ${ }^{11}$, Michael J. Hassett ${ }^{1,4}$ and Rinaa S. Punglia ${ }^{1,2^{*}}$

\begin{abstract}
Background: Although the 21-gene recurrence score (RS) assay is widely used to predict distant recurrence risk and benefit from adjuvant chemotherapy among women with hormone receptor-positive (HR+) breast cancer, the relationship between the RS and isolated locoregional recurrence (iLRR) remains poorly understood. Therefore, we examined the association between the RS and risk of iLRR for women with stage I-II, HR+ breast cancer.

Methods: We identified 1758 women captured in the national prospective Breast Cancer-Collaborative Outcomes Research Database who were diagnosed with stage I-II, HR+ breast cancer from 2006 to 2012, treated with mastectomy or breast-conserving surgery, and received RS testing. Women who received neoadjuvant therapy were excluded. The association between the RS and risk of iLRR was examined using competing risks regression.

Results: Overall, $19 \%$ of the cohort $(n=329)$ had a RS $\geq 25$. At median follow-up of 29 months, only 22 iLRR events were observed. Having a RS $\geq 25$ was not associated with a significantly higher risk of iLRR compared to a RS $<25$ (hazard ratio 1.14, 95\% confidence interval $0.39-3.36, P=0.81$ ). When limited to women who received adjuvant endocrine therapy without chemotherapy ( $n=1199 ; 68 \%$ of the cohort), having a RS $\geq 25$ ( $n=74$ ) was significantly associated with a higher risk of iLRR compared to a RS $<25$ (hazard ratio 3.66, 95\% confidence interval 1.07-12.5, $P=0.04$ ). In this group, increasing RS was associated with greater risk of iLRR (compared to RS $<18$, hazard ratio of $1.66,3.59$, and 7.06 , respectively, for RS 18-24, 25-30, and $\geq 31 ; P_{\text {trend }}=0.02$ ).
\end{abstract}

Conclusions: The RS was significantly associated with risk of iLRR in patients who did not receive adjuvant chemotherapy. The utility of the RS in identifying patients who have a low risk of iLRR should be further studied.

Keywords: Breast cancer, Locoregional recurrence, Recurrence score

\footnotetext{
* Correspondence: rpunglia@partners.org

${ }^{\dagger}$ David D. Yang and Daniela L. Buscariollo contributed equally to this work.

'Harvard Medical School, 25 Shattuck St, Boston, MA 02115, USA

2Department of Radiation Oncology, Dana-Farber/Brigham and Women's

Cancer Center, 75 Francis St, Boston, MA 02115, USA

Full list of author information is available at the end of the article
}

C C The Author(s). 2020 Open Access This article is licensed under a Creative Commons Attribution 4.0 International License, which permits use, sharing, adaptation, distribution and reproduction in any medium or format, as long as you give appropriate credit to the original author(s) and the source, provide a link to the Creative Commons licence, and indicate if changes were made. The images or other third party material in this article are included in the article's Creative Commons licence, unless indicated otherwise in a credit line to the material. If material is not included in the article's Creative Commons licence and your intended use is not permitted by statutory regulation or exceeds the permitted use, you will need to obtain permission directly from the copyright holder. To view a copy of this licence, visit http://creativecommons.org/licenses/by/4.0/ The Creative Commons Public Domain Dedication waiver (http://creativecommons.org/publicdomain/zero/1.0/) applies to the data made available in this article, unless otherwise stated in a credit line to the data. 


\section{Background}

Gene expression profiling has emerged as a useful clinical tool for patients with early-stage breast cancer. One such gene expression assay, the 21-gene recurrence score (RS), has been demonstrated to add utility to traditional clinicopathologic factors for prognosticating distant recurrence risk and predicting response to adjuvant chemotherapy in patients with early-stage, hormone receptor-positive $(\mathrm{HR}+)$ breast cancer [1-3]. Yet, the utility of the RS in assessing the risk of isolated locoregional recurrence (iLRR) is poorly understood.

Improving our ability to prognosticate the risk of iLRR among women with early-stage breast cancer could allow for a more individualized approach to use of postoperative radiation therapy (RT), an area of active investigation. The CALGB 9434 trial found that RT decreased the 10 -year locoregional recurrence from 10 to $2 \%$ for women age $\geq 70$ years with early-stage breast cancer treated with breast-conserving surgery (BCS) and tamoxifen [4]. Similarly, the PRIME II trial found that RT reduced local recurrence from 4.1 to $1.3 \%$ at 5 years for women age $\geq 65$ years with early-stage breast cancer treated with BCS and endocrine therapy [5]. Neither trial demonstrated improvement in metastasis-free or cancerspecific survival. Ongoing studies are investigating the use of gene expression profiling to prospectively select younger patients for whom RT may be avoided. Given the long natural history of $\mathrm{HR}+$ breast cancer, results from these trials will not be available for many years. In the interim, we examined the association between the RS and risk of iLRR for women with stage I-II, HR+ breast cancer.

\section{Methods}

The Breast Cancer-Collaborative Outcomes Research Database (BC-CORD) is a national, prospective database of patients with newly diagnosed breast cancer who received care at one of eight participating cancer centers in the United States. Using BC-CORD, we identified 1758 women who were diagnosed with stage I-II, HR+

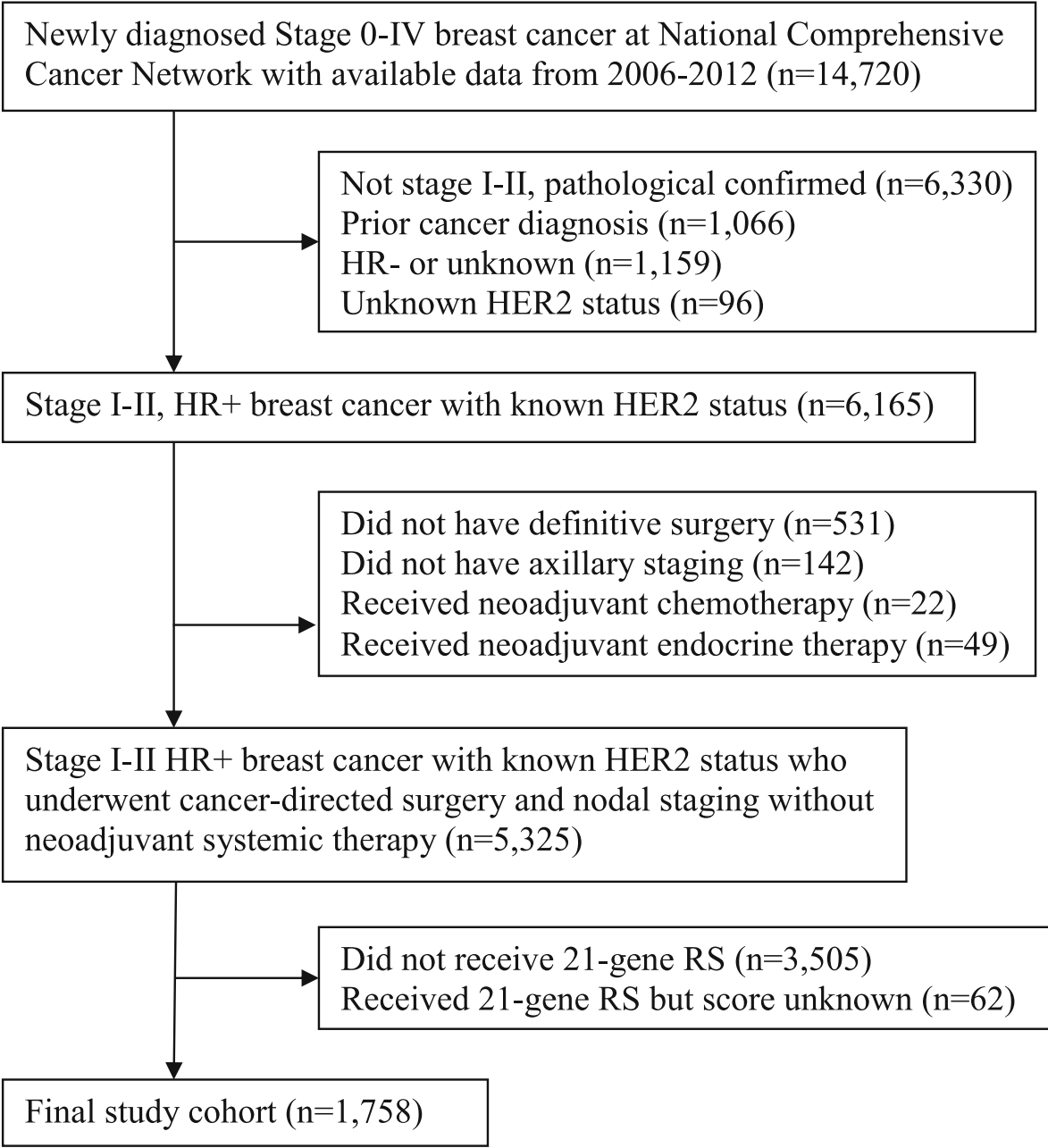

Fig. 1 Formation of the study cohort. HR: hormone receptor. RS: recurrence score 
breast cancer from 2006 to 2012, treated with mastectomy or BCS, and whose RS values were known (Fig. 1). Staging was determined using criteria from the American Joint Committee on Cancer (AJCC) Cancer Staging, 6th Edition [6], for patients diagnosed between 2006 through 2009, and AJCC Cancer Staging, 7th Edition, for patients diagnosed between 2010 through 2012 [7].

BC-CORD included follow-up for recurrence and survival status for all patients through January 31, 2013. Given the limited number of recurrences, additional follow-up through December 31, 2017 was obtained for 565 women treated at two institutions with records which were readily available.

Our primary analysis categorized RS as $\geq 25$ vs. $<25$. Secondary analyses categorized RS in four ordinal groups $(<18,18-24,25-30, \geq 31)$. Patient characteristics were compared using Pearson's $\chi^{2}$ test for categorical variables and the Wilcoxon rank-sum test for continuous variables. Cumulative incidence of iLRR (ipsilateral breast/chest wall or regional nodal recurrence) was estimated considering distant metastases and death as competing risks. The association between the RS and iLRR was examined using univariable competing risks regression [8]. As only 22 iLRR events were observed, the data were underpowered for multivariable analyses. To account for differences in treatment across scores, a subgroup analysis of patients treated with adjuvant endocrine therapy without chemotherapy was performed. All statistical testing was two-sided with significance set at $P<0.05$. Statistical analyses were performed using Stata 13.1 (StataCorp, College Station, TX). Institutional review board approval was obtained before undertaking this study.

\section{Results}

Study cohort characteristics appear in Table 1 . Most patients $(54 \%)$ had RS $<18$; $27 \%$ had RS of $18-24,10 \%$ had RS of $25-30$, and $9 \%$ had RS $\geq 31$. The median follow-up was 29 months (interquartile range 16-69 months). Overall, women with $R S \geq 25$ did not have a significantly

Table 1 Baseline patient characteristics of the entire cohort

\begin{tabular}{|c|c|c|c|}
\hline Characteristics & $\mathrm{RS}<25$ & $\mathrm{RS} \geq 25$ & $P$ \\
\hline Total, n (\%) & $1429(81)$ & $329(19)$ & - \\
\hline Age, median (interquartile range) & $53(47-61)$ & $56(48-64)$ & 0.002 \\
\hline Stage, n (\%) & & & 0.61 \\
\hline । & $996(70)$ & $234(71)$ & \\
\hline$\|$ & $433(30)$ & $95(29)$ & \\
\hline Surgery type, n (\%) & & & 0.46 \\
\hline Breast-conserving surgery & $1013(71)$ & $240(73)$ & \\
\hline Mastectomy & $416(29)$ & $89(27)$ & \\
\hline Adjuvant chemotherapy, n (\%) & & & $<0.001$ \\
\hline No & $1173(82)$ & $81(25)$ & \\
\hline Yes & $256(18)$ & $248(75)$ & \\
\hline Adjuvant hormonal therapy, $n(\%)$ & & & 0.009 \\
\hline No & $63(4)$ & $26(8)$ & \\
\hline Yes & $1366(96)$ & $303(92)$ & \\
\hline Adjuvant chemotherapy and hormonal therapy group, $\mathrm{n}(\%)$ & & & $<0.001$ \\
\hline Adjuvant hormonal therapy without chemotherapy & $1125(79)$ & $74(22)$ & \\
\hline Both adjuvant chemotherapy and hormonal therapy & $241(17)$ & $229(70)$ & \\
\hline Adjuvant chemotherapy without hormonal therapy & $15(1)$ & $19(6)$ & \\
\hline Neither adjuvant chemotherapy nor hormonal therapy & $48(3)$ & $7(2)$ & \\
\hline Postoperative radiation, $\mathrm{n}(\%)$ & & & 0.77 \\
\hline No & $397(28)$ & $94(29)$ & \\
\hline Yes & $1032(72)$ & $235(71)$ & \\
\hline Number of events, $n$ & & & - \\
\hline iLRR & 18 & 4 & \\
\hline DM without iLRR & 11 & 9 & \\
\hline Death without iLRR or DM & 7 & 6 & \\
\hline
\end{tabular}

$D M$ distant metastasis, iLRR isolated locoregional recurrence, $R S$ recurrence score 
Table 2 Baseline patient characteristics of patients by treatment subgroups

\begin{tabular}{|c|c|c|c|c|c|c|c|c|c|}
\hline & Treatment s & bgroup & & & & & & & \\
\hline Adjuvant hormonal therapy & Yes & & & Yes & & & No & & \\
\hline Adjuvant chemotherapy & No & & & Yes & & & Yes or No & & \\
\hline Characteristics & $\mathrm{RS}<25$ & $\mathrm{RS} \geq \mathbf{2 5}$ & $P$ & $\mathrm{RS}<25$ & $\mathrm{RS} \geq 25$ & $P$ & $\mathrm{RS}<25$ & $\mathrm{RS} \geq \mathbf{2 5}$ & $P$ \\
\hline Total, n (\%) & $1125(94)$ & $74(6)$ & - & $241(51)$ & $229(49)$ & - & $63(71)$ & $26(29)$ & - \\
\hline Age, median (interquartile range) & $54(48-62)$ & $65(54-70)$ & $<0.001$ & $49(44-56)$ & $54(46-62)$ & $<0.001$ & $52(46-63)$ & $53(45-63)$ & 0.96 \\
\hline Stage, n (\%) & & & 0.18 & & & 0.09 & & & 0.15 \\
\hline । & $799(71)$ & $58(78)$ & & $153(63)$ & $162(71)$ & & $44(70)$ & $14(54)$ & \\
\hline$\|$ & $326(29)$ & $16(22)$ & & $88(37)$ & $67(29)$ & & $19(30)$ & $12(46)$ & \\
\hline Surgery type, n (\%) & & & 0.03 & & & 0.37 & & & 0.81 \\
\hline Breast-conserving surgery & $812(72)$ & $62(84)$ & & $159(66)$ & $160(70)$ & & $42(67)$ & $18(69)$ & \\
\hline Mastectomy & $313(28)$ & $12(16)$ & & $82(34)$ & $69(30)$ & & $21(33)$ & $8(31)$ & \\
\hline Postoperative radiation, $\mathrm{n}(\%)$ & & & 0.84 & & & 0.86 & & & 0.59 \\
\hline No & $301(27)$ & $19(26)$ & & $66(27)$ & $61(27)$ & & $30(52)$ & $14(46)$ & \\
\hline Yes & $824(73)$ & $55(74)$ & & $175(73)$ & $168(73)$ & & $33(48)$ & $12(54)$ & \\
\hline Number of events, $n$ & & & - & & & - & & & - \\
\hline iLRR & 16 & 3 & & 1 & 1 & & 1 & 0 & \\
\hline DM without iLRR & 9 & 2 & & 2 & 6 & & 0 & 1 & \\
\hline Death without iLRR or DM & 7 & 3 & & 0 & 2 & & 0 & 1 & \\
\hline
\end{tabular}

$D M$ distant metastasis, iLRR isolated locoregional recurrence, $R S$ recurrence score

higher risk of iLRR compared to those with $\mathrm{RS}<25$ (hazard ratio $[\mathrm{HR}] 1.14,95 \%$ confidence interval [CI] 0.39-3.36, $P=0.81$ ).

Patient characteristics stratified by treatment subgroups (use of endocrine therapy and chemotherapy) are listed in Table 2. Among the 68\% $(n=1199)$ of patients treated with endocrine therapy without chemotherapy, $6 \%(n=74)$ had $\mathrm{RS} \geq 25$. In this group, with median follow-up of 30 months (interquartile range 16-72 months), RS $\geq 25$ was associated with a significantly higher risk of iLRR (HR 3.66, 95\% CI 1.07-12.5, $P=0.04$; Table 3; 60-month cumulative incidence of iLRR 10.3\% vs. $1.9 \%$; Fig. 2). Furthermore, the risk of iLRR was significantly larger with increasing RS, with HR of 1.66 ,

Table 3 Competing risks regression for the association between RS and iLRR

\begin{tabular}{lll}
\hline $\begin{array}{l}\text { Treatment } \\
\text { group }\end{array}$ & Competing risk regression for iLRR & $\begin{array}{l}60-\text { month } \\
\text { cumulative } \\
\text { incidence of iLRR } \\
(95 \% \mathrm{Cl})\end{array}$ \\
\cline { 2 - 3 } & $\mathrm{HR}(95 \% \mathrm{Cl})$ &
\end{tabular}

\begin{tabular}{|c|c|c|c|}
\hline \multicolumn{4}{|c|}{ Entire cohort } \\
\hline $\mathrm{RS}<25$ & 1.0 (reference) & & $1.8 \%(1.0-3.0 \%)$ \\
\hline $\mathrm{RS} \geq 25$ & $1.14(0.39-3.36)$ & 0.81 & $3.2 \%(1.0-7.6 \%)$ \\
\hline
\end{tabular}

Hormonal therapy without chemotherapy

\begin{tabular}{llll} 
RS $<25$ & 1.0 (reference) & & $1.9 \%(1.0-3.3 \%)$ \\
RS $\geq 25$ & $3.66(1.07-12.5)$ & 0.04 & $10.3 \%(2.2-25.7 \%)$ \\
\hline
\end{tabular}

Cl confidence interval, $H R$ hazard ratio, iLRR isolated locoregional recurrence, $R S$ recurrence score
3.59 , and 7.06, respectively, for RS of $18-24,25-30$, and $\geq 31$ relative to $\mathrm{RS}<18\left(P_{\text {trend }}=0.02\right.$; Table $4 ; 60$ month cumulative incidence of iLRR 1.2, 3.7, 7.3, and $33.3 \%$, respectively).

For the 18 women with RS $<25$ and iLRR, these iLRR occurred in the ipsilateral breast $(n=6)$, chest wall $(n=$ $4)$, ipsilateral lymph node $(n=6)$, other locoregional lymph node $(n=1)$, or concurrently in the breast/chest wall and locoregional lymph node outside the axilla $(n=$ $1)$. For the 4 women with RS $\geq 25$ and iLRR, these iLRR occurred in the ipsilateral breast $(n=1)$, chest wall $(n=$ $2)$, or ipsilateral lymph node $(n=1)$.

\section{Discussion}

Using a prospective cohort of women with stage I-II, $\mathrm{HR}+$ breast cancer, we found that a 21 -gene $\mathrm{RS} \geq 25$ was associated with an increased risk of iLRR relative to $<25$ among women who received adjuvant endocrine therapy without chemotherapy. Additionally, increasing RS was associated with higher risk of iLRR. Interestingly, a significant association between the RS and iLRR was not found for the entire cohort, likely because patients who received both adjuvant endocrine therapy and chemotherapy had a very low risk of iLRR (Table 2).

Strengths of our study include use of prospectively collected data from multiple institutions, which broadens the generalizability of the results. Our results support other reports of associations between RS and risk of locoregional recurrence [9-13]. Several limitations of 


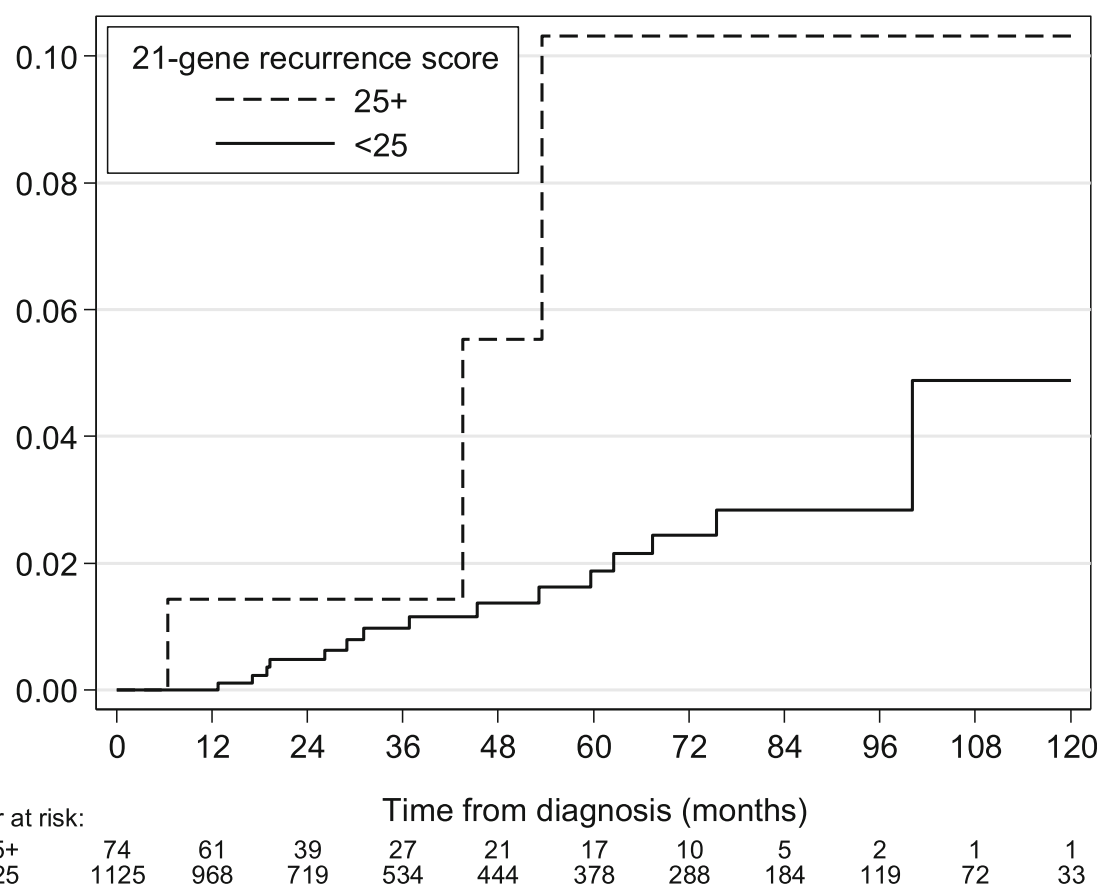

Fig. 2 Cumulative incidence of iLRR for patients who received adjuvant endocrine therapy without chemotherapy. iLRR: isolated locoregional recurrence

our study should be noted. First, our study had a relatively short follow-up of 29 months. Given the long natural history of HR+ breast cancers with locoregional recurrences which can occur beyond 5-10 years [14], our results should be interpreted with this limitation in mind. Second, there was a small number of iLRR events, which precluded multivariable adjustment for differences in treatment characteristics. To address this limitation, we performed a subgroup analysis of women who receive adjuvant endocrine therapy without chemotherapy, as chemotherapy use is directly influenced by RS. However, there were only 3 recurrences in the subgroup of patients who were treated with endocrine therapy without chemotherapy with $\mathrm{RS} \geq 25$. Additionally, detailed pathologic information including the presence of lymphovascular invasion, extranodal extension, and

Table 4 Competing risks regression for the association between increasing RS and iLRR for patients treated with adjuvant hormone therapy without chemotherapy

\begin{tabular}{|c|c|c|c|}
\hline \multirow{2}{*}{$\begin{array}{l}\text { Hormonal } \\
\text { therapy } \\
\text { without } \\
\text { chemotherapy }\end{array}$} & \multicolumn{2}{|c|}{ Competing risk regression for iLRR } & \multirow{2}{*}{$\begin{array}{l}60 \text {-month } \\
\text { cumulative } \\
\text { incidence of iLRR } \\
(95 \% \mathrm{Cl})\end{array}$} \\
\hline & $\mathrm{HR}(95 \% \mathrm{Cl})$ & $P_{\text {trend }}$ & \\
\hline $\mathrm{RS}<18$ & 1.0 (reference) & 0.02 & $1.2 \%(0.5-2.8 \%)$ \\
\hline RS $18-24$ & $1.66(0.59-4.66)$ & & $3.7 \%(1.5-7.7 \%)$ \\
\hline RS 25-30 & $3.59(0.78-16.6)$ & & $7.3 \%(1.0-22.7 \%)$ \\
\hline $\mathrm{RS} \geq 31$ & $7.05(0.97-51.3)$ & & $33.3 \%(0.9-77.4 \%)$ \\
\hline
\end{tabular}

$C /$ confidence interval, $H R$ hazard ratio, iLRR isolated locoregional recurrence, $R S$ recurrence score pathologic nodal staging, as well as information on why certain patients did not receive chemotherapy or endocrine therapy, were not available.

While data from ongoing trials studying omission of $\mathrm{RT}$ in patients selected by gene expression profiling are ongoing, our results may offer some insights into identifying patients with $\mathrm{HR}+$ breast cancer who have a very low risk of developing locoregional recurrences and therefore may not benefit in a clinically meaningful way from RT. It is important to note that given the low number of locoregional recurrences in our cohort, as well as large majority having received adjuvant $\mathrm{RT}$, conclusions regarding the value of the RS in predicting benefit from adjuvant RT cannot be drawn from our cohort. Other investigators have investigated whether the RS is predictive of benefit from RT using the Surveillance, Epidemiology, and End Results (SEER) database and the National Cancer Data Base (NCDB) [15]. Dong et al. examined the association of adjuvant RT with breast cancer-specific survival using a cohort of 13,246 patients from SEER with early-stage breast cancer treated with BCS [16]. They found that receipt of RT was associated with improved breast cancer-specific survival only for patients with intermediate RS. Goodman et al. investigated the association of PMRT with overall survival for patients with pT1-2N1 estrogen receptor-positive breast cancer using cohorts from the NCDB and SEER [17]. They found that PMRT was associated with improved overall survival only for patients with a low RS. Lastly, Zhang et al. studied the association between 
PMRT and both breast cancer-specific survival using a cohort from SEER for patients with pT1-2N1mic estrogen receptor-positive disease and did not have a significant association, regardless of the RS [18]. It is important to note that in these 3 studies, data on locoregional recurrences were not available, and as such, these studies do not shed light on the predictive value of RT on locoregional recurrence.

\section{Conclusions}

The RS was significantly associated with risk of iLRR in patients with early-stage, hormone receptor-positive breast cancer who received adjuvant endocrine therapy but not chemotherapy. The utility of the RS in identifying patients who have a low risk of iLRR should be further studied.

\section{Abbreviations}

BC-CORD: Breast Cancer-Collaborative Outcomes Research Database; BCS: Breast-conserving surgery; $\mathrm{Cl}$ : Confidence interval; HR: Hazard ratio; HR+: Hormone receptor-positive; iLRR: Isolated locoregional recurrence; LRR: Locoregional recurrence; RS: Recurrence score; RT: Radiation therapy

\section{Acknowledgements}

Not applicable.

\section{Authors' contributions}

DY interpreted the data, drafted the work, and substantively revised it. DB interpreted the data, drafted the work, and substantively revised it. AMC analyzed the data. SW analyzed the data. MH analyzed the data. RB contributed to the acquisition of the data and substantively revised it. ALC contributed to the acquisition of the data and substantively revised it. SJ contributed to the acquisition of the data and substantively revised it. SE contributed to the acquisition of the data and substantively revised it. BM contributed to the acquisition of the data and substantively revised it. JN contributed to the acquisition of the data and substantively revised it. AW contributed to the acquisition of the data and substantively revised it. $\mathrm{MH}$ interpreted the data, contributed to the acquisition of the data, and substantively revised it. RP interpreted the data, contributed to the acquisition of the data, and substantively revised it. All authors have approved the submitted version and agreed both to be personally accountable for the author's own contributions and to ensure that questions related to the accuracy or integrity of any part of the work, even ones in which the author was not personally involved, are appropriately investigated, resolved, and the resolution documented in the literature.

\section{Funding}

Not applicable

\section{Availability of data and materials}

The datasets used and/or analyzed during the current study are available from the corresponding author on reasonable request.

\section{Ethics approval and consent to participate}

Institutional review board approval from the Dana-Farber/Harvard Cancer Center was obtained before undertaking this study.

\section{Consent for publication}

Not applicable.

\section{Competing interests}

Adam Cohen reports receiving grants from Novartis, AbbVie, Merrimack, Bristol-Myers Squibb, Eli Lilly, Pfizer, and Cascadia, outside the submitted work. Richard Bleicher reports receiving personal fees from Genomic Health, outside the submitted work. All other authors have no relevant disclosures.

\section{Author details}

${ }^{1}$ Harvard Medical School, 25 Shattuck St, Boston, MA 02115, USA

2Department of Radiation Oncology, Dana-Farber/Brigham and Women's Cancer Center, 75 Francis St, Boston, MA 02115, USA. ${ }^{3}$ Division of Population Science, Dana-Farber Cancer Institute, 450 Brookline Ave, Boston, MA 02215, USA. ${ }^{4}$ Department of Medical Oncology, Dana-Farber/Brigham and Women's Cancer Center, 75 Francis St, Boston, MA 02115, USA. ${ }^{5}$ Department of Surgical Oncology, Fox Chase Cancer Center, 333 Cottman Ave, Philadelphia, PA 19111, USA. 'Department of Medicine, Division of Oncology, Huntsman Cancer Institute, 1950 Circle of Hope Dr, Salt Lake City, UT 84112, USA. ${ }^{7}$ Department of Surgery, University of Washington School of Medicine, Box 356410, Seattle, WA 98105, USA. ${ }^{8}$ Department of Surgical Oncology, Roswell Park Cancer Institute, 665 Elm St, Buffalo, NY 14203, USA. ${ }^{9}$ Department of Medical Oncology, Massachusetts General Hospital, 55 Fruit St, Boston, MA 02114, USA. ${ }^{10}$ Department of Diabetes and Cancer Discovery Science, City of Hope Comprehensive Cancer Center, 1500 East Duarte Road, Duarte, CA 91010, USA. ${ }^{11}$ Department of Oncology, Johns Hopkins University Sidney Kimmel Comprehensive Cancer Center, 401 N. Broadway, Weinberg, Baltimore, MD 21231, USA.

Received: 4 May 2020 Accepted: 10 August 2020

Published online: 17 August 2020

\section{References}

1. Paik S, Shak S, Tang G, Kim C, Baker J, Cronin M, et al. A multigene assay to predict recurrence of tamoxifen-treated, node-negative breast cancer. $\mathrm{N}$ Engl J Med. 2004;351(27):2817-26.

2. Paik S, Tang G, Shak S, Kim C, Baker J, Kim W, et al. Gene expression and benefit of chemotherapy in women with node-negative, estrogen receptorpositive breast cancer. J Clin Oncol. 2006;24(23):3726-34.

3. Sparano JA, Gray RJ, Makower DF, Pritchard Kl, Albain KS, Hayes DF, et al. Prospective validation of a 21-gene expression assay in breast cancer. $\mathrm{N}$ Engl J Med. 2015;373(21):2005-14.

4. Hughes KS, Schnaper LA, Bellon JR, Cirrincione CT, Berry DA, McCormick B, et al. Lumpectomy plus tamoxifen with or without irradiation in women age 70 years or older with early breast cancer: long-term follow-up of CALGB 9343. J Clin Oncol. 2013;31(19):2382-7.

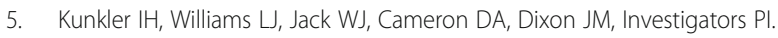
Breast-conserving surgery with or without irradiation in women aged 65 years or older with early breast cancer (PRIME II): a randomised controlled trial. Lancet Oncol. 2015;16(3):266-73.

6. AJCC. Cancer staging manual (6th Ed). New York: Springer; 2002.

7. AJCC. In: Edge SB, Byrd DR, Compton CC, Fritz AG, Greene FL, Trotti A, editors. Cancer staging manual. 7th ed. New York: Springer; 2010.

8. Fine JP, Gray RJ. A proportional hazards model for the subdistribution of a competing risk. J Am Stat Assoc. 1999;94(446):496-509.

9. Mamounas EP, Tang G, Fisher B, Paik S, Shak S, Costantino JP, et al. Association between the 21-gene recurrence score assay and risk of locoregional recurrence in node-negative, estrogen receptor-positive breast cancer: results from NSABP B-14 and NSABP B-20. J Clin Oncol. 2010;28(10): 1677-83.

10. Mamounas EP, Liu Q, Paik S, Baehner FL, Tang G, Jeong JH, et al. 21-gene recurrence score and Locoregional recurrence in node-positive/ER-positive breast cancer treated with chemo-endocrine therapy. J Natl Cancer Inst. 2017;109(4):1.

11. Jegadeesh NK, Kim S, Prabhu RS, Oprea GM, Yu DS, Godette KG, et al. The 21-gene recurrence score and locoregional recurrence in breast cancer patients. Ann Surg Oncol. 2015;22(4):1088-94.

12. Turashvili G, Chou JF, Brogi E, Morrow M, Dickler M, Norton L, et al. 21-gene recurrence score and locoregional recurrence in lymph node-negative, estrogen receptor-positive breast cancer. Breast Cancer Res Treat. 2017; 166(1):69-76.

13. Woodward WA, Barlow WE, Jagsi R, Buchholz TA, Shak S, Baehner F, et al. Association between 21-gene assay recurrence score and Locoregional recurrence rates in patients with node-positive breast cancer. JAMA Oncol. 2020;6(4):505.

14. Colleoni M, Sun Z, Price KN, Karlsson P, Forbes JF, Thurlimann B, et al. Annual Hazard rates of recurrence for breast cancer during 24 years of follow-up: results from the international breast cancer study group trials I to V. J Clin Oncol. 2016;34(9):927-35. 
15. Krug D, Baumann R, Budach W, Duma MN, Dunst J, Feyer P, et al. Commercially available gene expression assays as predictive tools for adjuvant radiotherapy? A critical review. Breast Care (Basel). 2020;15(2):118-26.

16. Dong Y, Zhang WW, Wang J, Sun JY, He ZY, Wu SG. The 21-gene recurrence score and effects of adjuvant radiotherapy after breast conserving surgery in early-stage breast cancer. Future Oncol. 2019;15(14):1629-39.

17. Goodman CR, Seagle BL, Kocherginsky M, Donnelly ED, Shahabi S, Strauss JB. 21-gene recurrence score assay predicts benefit of post-mastectomy radiotherapy in T1-2 N1 breast cancer. Clin Cancer Res. 2018;24(16):3878-87.

18. Zhang WW, Tong Q, Sun JY, Hua X, Long ZQ, Deng JP, et al. 21-gene recurrence score assay could not predict benefit of post-mastectomy radiotherapy in T1-2 N1mic ER-positive HER2-negative breast cancer. Front Oncol. 2019;9:270

\section{Publisher's Note}

Springer Nature remains neutral with regard to jurisdictional claims in published maps and institutional affiliations.

Ready to submit your research? Choose BMC and benefit from:

- fast, convenient online submission

- thorough peer review by experienced researchers in your field

- rapid publication on acceptance

- support for research data, including large and complex data types

- gold Open Access which fosters wider collaboration and increased citations

- maximum visibility for your research: over $100 \mathrm{M}$ website views per year

At $B M C$, research is always in progress.

Learn more biomedcentral.com/submissions 